\title{
Attachment, Autonomy, and Emotional Reliance: A Multilevel Model
}

\author{
Martin F. Lynch
}

This article reports a test of a multilevel model investigating how attachment security and autonomy contribute to emotional reliance, or the willingness to seek interpersonal support. Participants $(N=247)$ completed online measures of attachment, autonomy, emotional reliance, and vitality with respect to several everyday relationships. Multilevel model analyses identified a within-person process linking emotional reliance and vitality with both attachment and autonomy. Discussion focuses on the implications for both counseling and development.

Emotional reliance is a motivational construct reflecting the willingness to seek interpersonal support (Ryan, La Guardia, Solky-Butzel, Chirkov, \& Kim, 2005). Given the importance of interpersonal support during stressful events (Cohen, Sherrod, \& Clark, 1986; Pierce, Sarason, \& Sarason, 1991), the willingness to seek interpersonal support may be especially relevant to counselors and other helping professionals who are all too familiar with the motivational problems that can prevent clients from beginning or continuing in counseling. But what factors or processes are associated with the willingness to seek support, and how might this information be useful to counselors?

Recently, there has been some debate on the relative contributions of autonomy versus security in interpersonal processes (Mikulincer \& Shaver, 2007; Ryan, Brown, \& Creswell, 2007). Two theories suggest that emotional reliance may be one of the processes influenced by security, autonomy, or both. Attachment theory (Ainsworth, 1973; Bowlby, 1973) suggests that those who provide security are more likely to elicit trust and support-seeking behavior. Self-determination theory (SDT; Ryan \& Deci, 2000b) holds that people prefer to turn to partners who provide support for their basic psychological needs, particularly the need for autonomy (Ryan et al., 2005). Although the two constructs are not mutually exclusive-indeed, both theories consider attachment and autonomy to be important - they are assigned a different priority depending on the theoretical orientation. The present research attempts to address a gap in the literature by exploring the respective contributions of autonomy and security provision to emotional reliance. For counselors, understanding the role played by security and autonomy in the willingness to seek support may suggest ways of working with their clients that can enhance client motivation. The larger theoretical issue to which this question points is how an understanding of security and autonomy can be used to frame a positive theory of relationship processes (Mikulincer \& Shaver, 2007; Ryan et al., 2007). A secondary aim of the present study is to provide an example of how multilevel modeling (MLM) can be used by researchers in counseling and development (see also Lynch, 2012b).

\section{Emotional Reliance: The Willingness to Seek Interpersonal Support}

Support-seeking behavior and help-seeking behavior more generally have been fairly widely researched (Powell \& Kotschessa, 1995; Rickwood \& Braithwaite, 1994; Robbins \& Greenley, 1983; Vogel \& Wester, 2003). Emotional reliance as a motivational construct, however, received its first empirical support in a set of studies reported by Ryan et al. (2005), who defined emotional reliance as the willingness to rely on others for support during an emotionally salient event. Put differently, emotional reliance is the readiness to use one's interpersonal resources as a means to regulate one's emotions. In particular, the construct reflects the willingness to turn to specific partners when the emotions experienced are either unpleasant (e.g., anxious, depressed) or pleasant (e.g., proud, happy). In three studies, the researchers developed and validated a 10 -item scale and an abbreviated four-item version to measure the construct. It is noteworthy that they found that the willingness to turn to others for needed emotional supports, or emotional reliance, was associated with greater well-being, measured in terms of depressive symptoms, anxiety, selfactualization, self-esteem, and subjective vitality (a feeling of energy and aliveness; see Ryan \& Frederick, 1997). The association between emotional reliance and well-being held across gender and across four cultural groups (Korean, Russian, Turkish, and American), suggesting it is a fairly robust construct. Initial links to attachment and autonomy found by these researchers are reported as follows.

\section{Security and Support Seeking: An Attachment Theory Perspective}

Attachment theory (Ainsworth, 1973; Belsky, 2006; Bowlby, 1973; Hazan \& Shaver, 1994) offers an important developmental perspective on the possible antecedents of the willingness to turn to others for support during an emotionally salient event. The theory argues that attachment systems are activated during times of stress or danger. A secure attach-

\footnotetext{
Martin F. Lynch, Warner School of Education, University of Rochester. Correspondence concerning this article should be addressed to Martin F. Lynch, Warner School of Education, University of Rochester, LeChase Hall, Room 483, Rochester, NY 14627 (e-mail: mlynch@warner.rochester.edu).
}

(C) 2013 by the American Counseling Association. All rights reserved.

Journal of Counseling \& Development July 2013 - Volume 91 
ment provides the base to which the child can return during a stressful event and from which the child can safely explore when stress or threat are low. Attachments formed during childhood provide the internal working models through which subsequent relationship experiences are interpreted. On this basis, the theory postulates that, both during childhood and later in life, "attachment security works as ... an internal guidance system, filtering and appraising experiences in the world, especially social experiences, and thereby guiding behavior, especially behavior in close relationships," with regulation of emotion being considered "central to current conceptions of attachment theory" (Belsky, 2002, p. 166; for a similar argument, see also NICHD Early Childcare Research Network, 2006).

Research has found that although securely attached preschool children were less dependent on their teachers, they were more willing to call on them for assistance when they themselves were unable to manage a challenge (Sroufe, Fox, \& Pancake, 1983). Furthermore, adult attachment styles appear to be related to help-seeking intentions (Vogel \& Wei, 2005) and behaviors (Florian, Mikulincer, \& Bucholtz, 1995; Hazan \& Shaver, 1987), perhaps by predisposing the individual to view others as reliable or unreliable and as caring or indifferent (Sarason, Pierce, \& Sarason, 1990; Wallace \& Vaux, 1993). Accordingly, it is reasonable to assume that attachment style may play a role in the willingness to turn to others for emotional support at a time of need. Specifically, although those who are securely attached may exhibit greater willingness to turn to others and may benefit from such willingness, those who are anxiously attached may very much desire others' emotional support but may not achieve the same benefits from their readiness to seek it (Vogel \& Wei, 2005). Those with an avoidant attachment style would be unlikely to exhibit high levels of emotional reliance.

Although attachment has traditionally been thought of as a relatively stable, trait-like individual difference, current thinking is that attachment may vary depending on the relationship target (Baldwin, Keelan, Fehr, Enns, \& Koh-Rangarajoo, 1996; Kobak, 1994; La Guardia, Ryan, Couchman, \& Deci, 2000; Mikulincer \& Shaver, 2007; Shaver, Belsky, \& Brennan, 2000). Accordingly, one's willingness to turn to a particular partner for emotional support may in part depend on the relative security of one's attachment in that specific relationship.

As part of their validation of the emotional reliance construct, Ryan et al. (2005) found that it was negatively associated with problematic forms of dependence and with attachment avoidance and positively associated with attachment security, thus suggesting some dispositional correlates of the willingness to seek emotional support. These researchers did not, however, test whether emotional reliance varied with relationship-specific attachment or further explore the theoretical link between emotional reliance and attachment.

\section{Autonomy and Autonomy Support: An SDT Perspective}

Along with competence and relatedness, autonomy is considered to be a basic psychological need within the SDT tradition (Ryan \& Deci, 2000b). SDT defines basic needs functionally as that which the human person requires in order to grow and to thrive emotionally, psychologically, and interpersonally across the life span. This assumption has been tested empirically in numerous studies demonstrating that satisfaction of the basic needs is associated with internal motivation, well-being, and thriving (Ryan \& Deci, 2000a), including cross-culturally (e.g., Lynch, La Guardia, \& Ryan, 2009). Because autonomy is thought to have particular relevance for emotional reliance, it is important to clarify how it is understood within SDT.

In SDT, autonomy derives from the existential tradition. It implies the feeling of volition and choice rather than feeling pressured or coerced in one's actions. In relationships, being supportive of another's autonomy means being attentive to and interested in the other person's perspective as well as fostering choice rather than trying to control the other person or to impose one's own agenda (Ryan, 1993). It is important to note that autonomy is not equated with independence in SDT: A person can autonomously choose to depend or rely on another person for resources and supports. Indeed, research suggests that even during adolescence, the period during which relying on oneself or independence has traditionally been thought to play an important developmental role, freely choosing to rely on others, including one's parents, for emotional supports can have important benefits for well-being (Ryan \& Lynch, 1989). In their validation study, Ryan et al. (2005) found that people endorsed greater emotional reliance when they experienced satisfaction of their basic needs, including the need for autonomy, in their relationships.

A limitation of existing research on autonomy support is that researchers do not always control for individual differences in level of autonomy (Vansteenkiste, Niemiec, \& Soenens, 2010). Some people may show higher levels of autonomy in their daily behavior, and indeed autonomy can be measured as a trait or disposition (Sheldon \& Deci, 1996). In this regard, it is possible that support for autonomy matters more for those who are themselves highly autonomous and therefore may be more likely to value autonomy support in their relationships, in a kind of "match hypothesis" (Markus \& Kitayama, 1991). SDT, however, suggests that, if autonomy is truly a basic need, its importance should not be moderated by one's dispositional level of autonomy. This is because, in SDT, basic psychological needs are believed to be universal. The present study thus seeks to advance the counseling profession's understanding of the role of autonomy support in emotional reliance by controlling for individual differences in autonomy and by allowing autonomy to compete with attachment security. 


\section{The Present Study}

The present study tested the relative contributions of two constructs, attachment security and autonomy, to emotional reliance or the willingness to seek support. Both constructs were measured at two levels: at the between-persons level, reflecting individual differences in levels of security and autonomy, and at the within-person level, reflecting relationship-specific variations in those constructs. In line with attachment theory, it was expected that emotional reliance would be associated with greater security (Hypothesis 1 [H1]); in line with SDT, the willingness to seek emotional support should be positively associated with autonomy (Hypothesis 2 [H2]). To replicate prior findings, I also tested the link between emotional reliance and well-being, such that the willingness to turn to one's partners for support should be associated with greater well-being (Hypothesis 3 [H3]). However, as predicted by attachment theory, although those who are anxiously attached may seek greater emotional supports from their partners, they may be less likely to benefit from their emotional reliance; that is, the link between emotional reliance and well-being should be moderated by anxiety (Hypothesis 4 [H4]).

\section{Method}

\section{Participants}

Participants $(N=247 ; 81.4 \%$ female; age: $M=22.9$ years, $S D=5.49$ ) were drawn from a pool of approximately 2,000 undergraduate psychology majors at a large university in the southeastern United States. Self-reported ethnic background of study participants was $6.5 \%$ Asian/Pacific Islander, $12.5 \%$ Black/African American, 55\% Caucasian/White, 19\% Hispanic/Latin American, and 7\% other, which was roughly representative of the larger student body at this university.

\section{Procedure}

Students registered to participate in the study through the ExperimenTrak system maintained by the department of psychology in which the author was a faculty member at the time. Participants completed an online survey in exchange for course credit. Participation was voluntary and anonymous, and students could withdraw from the study at any time without penalty, in keeping with requirements of the study's institutional review board approval.

\section{Measures}

This study makes use of a data analytic strategy known as MLM, described more fully as follows. Among other things, MLM allows researchers to move beyond the traditional focus on individual differences and between-persons factors to study within-person processes. Accordingly, in the present study, data were collected at two levels of analysis, the between-persons level (referred to as Level 2 in the MLM tradition) and the within-person level (referred to as Level 1).

\section{Level 2 Measures}

When MLM is used to test within-person processes, as in the present study, variables that are more trait-like or dispositional are called Level 2 explanatory variables. The study included several Level 2 variables: attachment, trait autonomy, and vitality.

Attachment. The Relationship Questionnaire, adapted from Hazan and Shaver's (1987) well-validated measure of attachment styles designed for use with adults (see Bartholomew \& Horowitz, 1991, for the validation study of the version used here), was used as an individual difference measure of attachment. Participants were presented with four, singleitem, self-report attachment style prototypes, reflecting secure, dismissing, preoccupied, and fearful attachment styles. Participants rated how accurate a description each of the four prototypical statements was of them on a Likert-type scale of 1 (not at all accurate) to 7 (very accurate). Conceptually, the secure style, characterized by "valuing of intimate friendships, [and] the capacity to maintain close relationships without losing personal autonomy" (p. 228), is contrasted in Bartholomew and Horowitz's (1991) model with the fearful style, characterized by "an avoidance of close relationships because of fear of rejection," whereas the dismissing style, characterized by "downplaying of the importance of close relationships ... [and] emphasis on independence and selfreliance," is contrasted with the preoccupied style, characterized by "overinvolvement in close relationships, [and] a dependence on other people's acceptance for a sense of personal well-being" (p. 228). In their validation study, Bartholomew and Horowitz found that contrasting styles were most strongly negatively correlated with each other (between secure and fearful, $r=-.55, p<.01$; between preoccupied and dismissing, $r=-.50, p<.01$; smaller or nonsignificant correlations between noncontrasting styles). The same pattern was observed in the present sample (between secure and fearful, $r=-.28, p<.01$; between preoccupied and dismissing, $r=$ $-.25, p<.01$; smaller or nonsignificant correlations between noncontrasting styles).

Trait autonomy. The Self-Determination Scale was used as a measure of dispositional autonomy, or the tendency to experience oneself as autonomous. The scale was originally validated by Sheldon and Deci (1996) and has been used in numerous studies (e.g., Sheldon, Ryan, \& Reis, 1996; Thrash $\&$ Elliot, 2002). The scale consists of 10 paired statements reflecting autonomy versus control. Participants indicate on a scale of 1 to 5 which of the two statements, labeled $A$ and $B$, feels more true for them, where $1=$ only $A$ feels true and $5=$ only $B$ feels true. An example is "I always feel like I choose the things I do" versus "I sometimes feel that it's not really me choosing the things I do." As reported by Sheldon et al. (1996), internal consistency alphas have ranged from .85 to .93 across numerous samples, with adequate test-retest reliability (.77 over a period of 8 weeks). Construct validity has been demonstrated by its strong associations with well-being 
(Sheldon \& Deci, 1996; Sheldon et al., 1996) and resistance to peer pressure (Grow, Sheldon, \& Ryan, 1994), among others. Internal consistency reliability for the present sample was alpha $=.83$.

Vitality (global). Ryan and Frederick's (1997) six-item Subjective Vitality Scale was administered twice, at Level 2 as a measure of overall well-being and at Level 1 as a predictor of vitality in relationships (see the following). It assesses the experience of aliveness, energy, and vigor. Participants rate items on a Likert-type scale of 1 (not at all) to 7 (very much) in terms of their experience over the past month. The scale has been used in many studies, including the emotional reliance validation studies mentioned previously (Ryan et al., 2005), and has shown excellent reliability and validity, with strong associations to measures of both emotional and physical well-being (see Bostic, Rubio, \& Hood, 2000). In their initial validation studies, Ryan and Frederick (1997) obtained internal consistency alphas ranging from .83 to .86 (in the present sample, $\alpha=.90$ ).

\section{Level 1 (Within-Person) Measures}

Several variables were measured at the within-person level of analysis, referred to as Level 1 within MLM: attachment, autonomy support, emotional reliance, and vitality. All within-person measures were completed with respect to each of four target relationships (with mother, father, best friend, and romantic partner), chosen for their likely importance to college students.

Attachment. Reflecting the more recent emphasis on relationship-specific attachments (La Guardia et al., 2000; Mikulincer \& Shaver, 2007), the Experiences in Close Relationships Scale (Brennan, Clark, \& Shaver, 1998) was used as a measure of attachment style specific to each relationship. The scale consists of 36 items and yields subscale scores for attachment avoidance and attachment anxiety. Attachment security is not measured directly but is reflected in low scores on both subscales. Participants rate each item on a Likert-type scale of 1 (strongly disagree) to 7 (strongly agree). Examples are "I worry a lot about my relationship with my mother" (attachment anxiety) and "Just when my mother starts to get close to me I find myself pulling away" (attachment avoidance). In their validation study, Brennan et al. (1998) found that the avoidance scale correlated highly with several existing scales that measured avoidance and discomfort in close relationships, whereas the anxiety scale correlated highly with scales that measured anxiety, jealousy, fear of rejection, and preoccupation with attachment. They reported internal consistencies of .94 for avoidance and .91 for anxiety. In the present sample, across relationships, alphas ranged from .92 to .94 for avoidance and from .88 to .93 for anxiety.

Autonomy support. The Autonomy Supportive Relationships Scale is a six-item scale based on the Health Care Climate Questionnaire (Williams \& Deci, 2001), which has been adapted to assess autonomy support versus control from important others (Williams et al., 2006). Participants rate each item on a Likert-type scale of 1 (strongly disagree) to 7 (strongly agree). Williams et al. (2006) found strong associations between perceived partner autonomy support and outcomes such as perceived autonomy and perceived competence for target health behaviors, as well as health outcomes such as 6-month prolonged abstinence from tobacco among those trying to quit smoking; they reported internal consistency alphas between .87 and .95 (.89 to .91 in the present sample). Sample items include "I believe my mother is very understanding of me" and "I feel controlled by my mother" (reverse scored).

Emotional reliance. To reduce participant fatigue, I assessed emotional reliance within each relationship using the abbreviated four-item version of the Emotional Reliance scale developed and validated by Ryan et al. (2005), as noted earlier. Items are rated on a 7-point Likert-type scale $(1=$ strongly disagree, $7=$ strongly agree). Scores are calculated as the mean of items for each relationship. Items include "If I were feeling alone or depressed, I would be willing to go to (my mother)," "If I were feeling anxious or scared about something, I would be willing to go to (my mother)," "If I were feeling very bad about myself and needed a boost, I would be willing to go to (my mother)," and "If I were feeling happy or had good news, I would be willing to go to (my mother)." Ryan et al. (2005) reported internal consistency alphas from .91 to .97 (.94 to .96 in the present sample).

Vitality. The Subjective Vitality Scale (Ryan \& Frederick, 1997), described previously, was used to measure vitality within relationships, with participants rating each of the four relationships according to the vitality they experienced with each partner. Thus, vitality was measured both globally (Level 2) and with respect to each relationship (Level 1). Controlling for global vitality should allow for a test of whether explanatory variables (e.g., emotional reliance, attachment security, autonomy) accounted for change in relationship-specific vitality, relative to one's baseline. Alphas for relationship-specific vitality ranged from .95 to .97 .

\section{Data Analytic Strategy}

In the present study, MLM was conducted by means of the mixed models linear program in SPSS Version 19 (Fleeson, 2007; Lynch, 2012b) to test the within-person process describing the relation between explanatory and outcome variables across four relationship targets (mother, father, best friend, and romantic partner). MLM is a relatively recent data analytic technique that provides a way to analyze data that are hierarchically structured. Data are structured hierarchically when one variable is nested within another variable. Two typical configurations of hierarchically structured data that may be of particular interest to researchers in counseling and human development are when people are nested within some wider ecological setting (such as students nested within classrooms, or classrooms nested within schools) and when 
variables are nested within the person (e.g., experiences of need satisfaction and feelings of depression measured across multiple occasions or across multiple relationships). The latter configuration is especially useful in testing for the presence of within-person processes, as in the present study, in that both the explanatory variables (e.g., attachment, autonomy) and outcome variable (e.g., emotional reliance) are allowed to vary within each participant across occasions or particular relationships. Notably, one of the advantages of MLM over traditional regression approaches is that MLM allows for the possibility that the relationship between explanatory and outcome variables may be different for different people, that is, that it may be stronger, absent, or in the opposite direction for some people in the sample. Specifically, MLM provides a test of the possibility that between-persons differences in the relationship between variables are not due to chance, denoted by the standard deviation on the main effect. Accordingly, the output provided by SPSS includes two coefficients: a coefficient similar to the beta in a traditional regression analysis, reflecting the strength of the association between variables for the typical individual in the sample, and the standard deviation on this coefficient. Tests of significance are provided for both. (Note that the standard deviation is provided only for Level 1 explanatory variables because Level 2 variables remain constant. If the standard deviation is significant, that suggests the process relating the explanatory variable to the outcome is different [stronger or weaker] across individuals in the sample. Interested readers are referred to Fleeson, 2007, and Lynch, 2012b, for more detailed information on conceptual and practical issues involved in conducting and reporting MLM analyses.)

In the first analysis, which tested the link between emotional reliance and the attachment and autonomy dimensions (H1, H2), emotional reliance (assessed for each relationship) was entered in the model as the dependent variable. Autonomy support, attachment anxiety, and attachment avoidance (all measured with respect to each of four relationships) were entered as within-person Level 1 explanatory variables; trait autonomy and the secure, dismissing, preoccupied, and fearful attachment styles were entered as between-persons
Level 2 variables. Two-way interactions were also tested. Figure 1 shows a model testing H1, in which relationshipspecific attachment and dispositional attachment style predict relationship-specific emotional reliance. In the actual analysis, $\mathrm{H} 1$ and $\mathrm{H} 2$ were tested simultaneously.

In the second analysis, testing the link between emotional reliance and well-being (H3), relationship-specific vitality was entered in the model as the dependent variable. Emotional reliance was entered as a within-person Level 1 explanatory variable, as were autonomy support, attachment anxiety, and attachment avoidance. In the interest of parsimony, at Level 2 only, global vitality, trait autonomy, and the secure attachment style were entered as between-persons explanatory variables. Including global vitality at Level 2 allowed the analysis to test the effect of the explanatory variables on relationship vitality by controlling for participants' baseline level of vitality. Two-way interaction terms were also included with a focus on testing $\mathrm{H} 4$, which predicted that the relation between emotional reliance and well-being would be moderated by attachment anxiety.

All continuous within-person Level 1 explanatory variables (e.g., autonomy support) were mean centered within each person in order to account for between-persons variance and ensure that results reflected the proposed within-person process (see Fleeson, 2007; Lynch, 2012b). Continuous Level 2 variables were centered on the group mean. An initial analysis entered sex as a factor, but although there was a significant main effect such that the effect of being male on emotional reliance was negative, there were no significant interactions by sex for any of the explanatory variables. Accordingly, reported results collapse across sex.

\section{Analysis of Power}

Balkin and Sheperis (2011) advocated reporting results of statistical power analysis, or the likelihood of finding a statistically significant result, in all quantitative studies. Although some guidelines exist for determining power in MLM (Reise \& Duan, 1999), Snijders (2005) stated that, for models in which there are two or more explanatory variables that are likely to be correlated (as in the present study), there are at

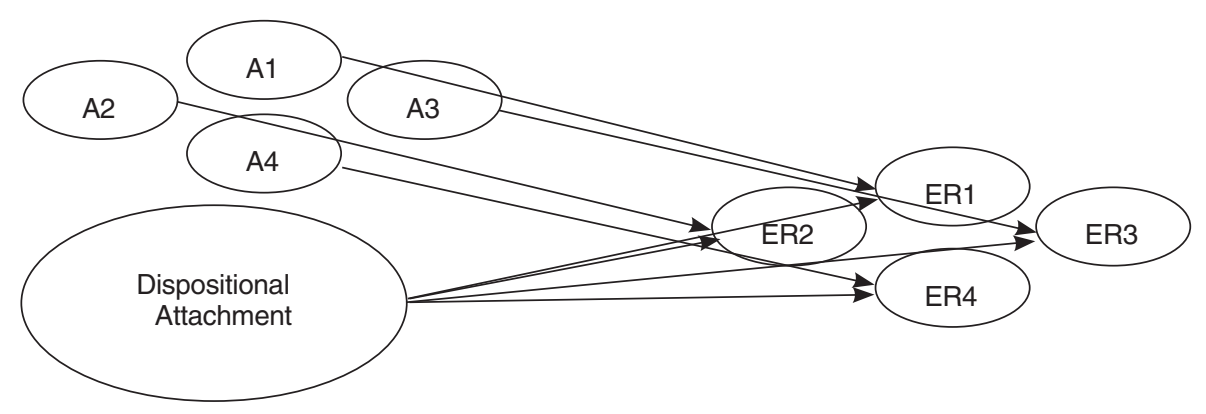

FIGURE 1

Multilevel Model Showing Impact of Level 1 Attachment (A) Across Partners (A1-A4) and Level 2 Dispositional Attachment on Emotional Reliance (ER) Across Partners (ER1-ER4) 
present no clear formulas for determining power. To offset concerns about power to some degree, I used the more conservative significance level of alpha $=.01$, thus reducing the probability of making a Type I error (finding an association when one does not exist).

\section{Results}

\section{The Process Relating Emotional Reliance to Attachment and Autonomy ( $\mathrm{H} 1, \mathrm{H} 2)$}

As shown in Table 1, unstandardized betas indicate that all three of the within-person Level 1 variables were significantly associated with emotional reliance: For the typical individual, there was a within-person process linking emotional reliance positively with both autonomy support and attachment anxiety but negatively with attachment avoidance, as predicted. Participants indicated greater willingness to turn to those partners with whom they experienced greater autonomy support or attachment anxiety and were less likely during an emotionally salient event to turn to those with whom they experienced an avoidant attachment. As previously noted, MLM provides a test of the possibility that the within-person process differed significantly across individuals. The results of this test, denoted by the standard deviations in Table 1, indicate that for each of the three within-person variables, the process did differ across individuals: For some people the association was stronger than for others. I compared the magnitude of the standard deviation to that of the coefficient it modifies (Fleeson, 2007; Lynch, 2012b) and found that, for each of the explanatory variables, the within-person process was in the same direction for each individual.

In terms of the between-persons variables, there were significant positive associations between emotional reliance and both trait autonomy and attachment security, but dismissing, preoccupied, and fearful attachment styles were unrelated to emotional reliance. People who were themselves more autonomous or more securely attached (in terms of their general attachment style) were more likely to endorse being willing to turn to their partners during emotionally salient events. (Note that there is no standard deviation reported for Level 2 variables, because those variables do not differ across relationship partners.) Thus, results at both the within-person and between-persons levels supported the predictions made on the basis of attachment theory and SDT. Comparing betas at both levels, however, indicates that emotional reliance was more strongly associated with the autonomy than the attachment dimension, supporting the prediction of SDT rather than that of attachment theory.

Regarding interactions, only one attained significance using the more conservative cutoff of alpha $=.01$. For those who experienced an avoidant attachment with a partner, the impact on emotional reliance was more positive (they were more likely to endorse emotional reliance) if they also experienced autonomy support from the partner. It is noteworthy that the
TABLE 1

\section{The Within-Person Process Relating Perceived Autonomy Support, Attachment Anxiety, and Attachment Avoidance to Emotional Reliance, With Trait Autonomy and Attachment Dimensions and Their Interactions}

\begin{tabular}{|c|c|c|}
\hline Level and Explanatory Variable & $\mathrm{Tl}^{\mathrm{a}}$ & $S D^{\mathrm{b}}$ \\
\hline \multicolumn{3}{|l|}{ Level 1} \\
\hline Autonomy support & $.49^{*}$ & $.05^{\star}$ \\
\hline Attachment anxiety & $.02^{*}$ & $.00^{*}$ \\
\hline Attachment avoidance & $-.04^{*}$ & $.00^{*}$ \\
\hline \multicolumn{3}{|l|}{ Level 2} \\
\hline Trait autonomy & $.54^{*}$ & - \\
\hline Secure attachment & $.12^{*}$ & - \\
\hline Dismissing attachment & -.06 & - \\
\hline Preoccupied attachment & .03 & - \\
\hline Fearful attachment & .04 & - \\
\hline \multicolumn{3}{|l|}{ Interactions } \\
\hline Autonomy Support × Anxiety & .00 & - \\
\hline Autonomy Support $\times$ Avoidance & $.01^{*}$ & - \\
\hline Autonomy Support $\times$ Trait Autonomy & -.05 & - \\
\hline Autonomy Support $\times$ Secure & .04 & - \\
\hline Autonomy Support $\times$ Dismissing & .04 & - \\
\hline Autonomy Support $\times$ Preoccupied & .05 & - \\
\hline Autonomy Support $\times$ Fearful & .02 & - \\
\hline Anxiety $\times$ Avoidance & .00 & - \\
\hline Anxiety $\times$ Trait Autonomy & .00 & - \\
\hline Anxiety $\times$ Secure & .00 & - \\
\hline Anxiety $\times$ Dismissing & .00 & - \\
\hline Anxiety $\times$ Preoccupied & .00 & - \\
\hline Anxiety $\times$ Fearful & .00 & - \\
\hline Avoidance $\times$ Trait Autonomy & .00 & - \\
\hline Avoidance $\times$ Secure & .00 & - \\
\hline Avoidance $\times$ Dismissing & .00 & - \\
\hline Avoidance $\times$ Preoccupied & .00 & - \\
\hline Avoidance $\times$ Fearful & .00 & - \\
\hline Trait Autonomy $\times$ Secure & -.02 & - \\
\hline Trait Autonomy × Dismissing & .07 & - \\
\hline Trait Autonomy $\times$ Preoccupied & .02 & - \\
\hline Trait Autonomy $\times$ Fearful & .02 & - \\
\hline Secure $\times$ Dismissing & .02 & - \\
\hline Secure $\times$ Preoccupied & -.01 & - \\
\hline Secure $\times$ Fearful & -.04 & - \\
\hline Dismissing $\times$ Preoccupied & -.01 & - \\
\hline Dismissing $\times$ Fearful & .04 & - \\
\hline Preoccupied $\times$ Fearful & .00 & - \\
\hline
\end{tabular}

Note. The dash indicates data are not reported. $\mathrm{TI}=$ typical individual. a Unstandardized coefficients. ${ }^{\mathrm{b}}$ Across individuals.

${ }^{*} p<.01$.

interaction between autonomy support and trait autonomy was not significant; as predicted by SDT, people were more likely to turn to partners from whom they experienced autonomy support, regardless of whether they themselves were dispositionally more autonomous, thus failing to support the match hypothesis.

\section{The Process Relating Well-Being to Emotional Reliance (H3, H4)}

Table 2 shows that, for the typical individual, there was a within-person process linking vitality in relationships to emotional reliance, autonomy support, attachment anxiety, 
TABLE 2

\section{The Within-Person Process Relating Emotional Reliance, Perceived Autonomy Support, Attachment Anxiety, and Attachment Avoidance to Vitality in Relationships, With Global Vitality, Trait Autonomy, and Attachment Security and Their Interactions}

\begin{tabular}{|c|c|c|}
\hline Level and Explanatory Variable & $\mathrm{Tl}^{\mathrm{a}}$ & $S D^{\mathrm{b}}$ \\
\hline \multicolumn{3}{|l|}{ Level 1} \\
\hline Emotional reliance & $.32^{*}$ & $.32^{*}$ \\
\hline Autonomy support & $.35^{\star}$ & .27 \\
\hline Attachment anxiety & $.02^{*}$ & $.02^{*}$ \\
\hline Attachment avoidance & $-.01^{*}$ & $.02^{*}$ \\
\hline \multicolumn{3}{|l|}{ Level 2} \\
\hline Global vitality & $.18^{*}$ & - \\
\hline Trait autonomy & $.32^{*}$ & - \\
\hline Secure attachment & .10 & - \\
\hline \multicolumn{3}{|l|}{ Interactions } \\
\hline Emotional Reliance $\times$ Autonomy Support & -.04 & - \\
\hline Emotional Reliance $\times$ Anxiety & .00 & - \\
\hline Emotional Reliance $\times$ Avoidance & .00 & - \\
\hline Emotional Reliance $\times$ Global Vitality & .06 & - \\
\hline Emotional Reliance $\times$ Trait Autonomy & -.13 & - \\
\hline Emotional Reliance $\times$ Secure & .03 & - \\
\hline Autonomy Support $\times$ Anxiety & .00 & - \\
\hline Autonomy Support $\times$ Avoidance & -.01 & - \\
\hline Autonomy Support × Global Vitality & -.02 & - \\
\hline Autonomy Support $\times$ Trait Autonomy & -.03 & - \\
\hline Autonomy Support $\times$ Secure & .03 & - \\
\hline Anxiety $\times$ Avoidance & .00 & - \\
\hline Anxiety $\times$ Global Vitality & .00 & - \\
\hline Anxiety $\times$ Trait Autonomy & .01 & - \\
\hline Anxiety $\times$ Secure & .00 & - \\
\hline Avoidance $\times$ Global Vitality & .00 & - \\
\hline Avoidance $\times$ Trait Autonomy & $-.02^{*}$ & - \\
\hline Avoidance $\times$ Secure & .00 & - \\
\hline Global Vitality $\times$ Trait Autonomy & .12 & - \\
\hline Global Vitality $\times$ Secure & .07 & - \\
\hline Trait Autonomy $\times$ Secure & -.04 & - \\
\hline
\end{tabular}

Note. The dash indicates data are not reported. $\mathrm{TI}=$ typical individual. aUnstandardized coefficients. ${ }^{\mathrm{b}}$ Across individuals.

${ }^{*} p<.01$.

and attachment avoidance. People experienced greater vitality in relationships with partners to whom they were willing to turn for emotional support, and with whom they experienced greater autonomy support or attachment anxiety, but less attachment avoidance. Attachment anxiety's positive relation to vitality was not expected. The standard deviations on these coefficients reached the threshold for significance for emotional reliance and the two attachment constructs, suggesting that the strength (or even the presence, for emotional reliance) of the within-person process differed for different individuals.

In terms of the between-persons or individual difference factors, vitality in one's relationships was positively associated with both global vitality and trait autonomy. People who were dispositionally more autonomous reported greater vitality in their relationships, controlling for baseline levels of vitality. Only one interaction reached significance: For those who were high in trait autonomy, having an avoidant attachment in one's relationships was even more negatively associated with relationship vitality. Notably, the interaction between emotional reliance and attachment anxiety was not significant, failing to support the prediction that those who were anxiously attached might have difficulty experiencing the well-being benefits of emotional reliance on their partners. Again, the impact of autonomy support was not moderated by trait autonomy, failing to support the match hypothesis with respect to vitality.

\section{Discussion}

The present study used MLM to disentangle the contributions of autonomy and attachment to emotional reliance, or the willingness to seek interpersonal support during an emotionally salient event. Results identified a within-person process such that people were more willing to turn to partners with whom they experienced autonomy support or attachment anxiety but were less willing to turn to partners with whom they experienced attachment avoidance, supporting predictions made by SDT and attachment theory (H1, H2). Individual differences in trait autonomy and attachment were also significant, such that those who were dispositionally more autonomous or more secure in their attachment style were more likely to endorse the willingness to turn to their partners. It is important to note that, at both the within-person and between-persons levels of analysis, emotional reliance was more strongly linked with autonomy than security, as predicted by SDT. The study also found a within-person process linking emotional reliance with greater well-being (H3), operationalized as vitality in one's relationships, confirming earlier findings (Ryan et al., 2005). The prediction that the relation between emotional reliance and well-being would be moderated by attachment anxiety (H4) was not supported.

By allowing attachment and autonomy to compete for variance in emotional reliance, the present study addressed an issue that may have importance for both counselors and those in human development. For those in the field of human development, the present research provided additional confirmation of the importance of attachment security in relationship processes. It is important that the study both confirmed the role of attachment security as a dispositional style, which in classic attachment theory derives from the early caregiver relationship, and highlighted the relevance of relationship-specific attachments, as more recent researchers have emphasized. In particular, attachment security was positively related to emotional reliance, indicating the potential importance of security in emotion regulation (Belsky, 2002). Autonomy also proved to be important; indeed, its contributions to emotional reliance (see Table 1) and to vitality (see Table 2) were substantially greater than those of attachment. Although further research is needed, the present study supports the idea put forward by Ryan et al. (2007) that autonomy may be even more fundamental in relationship processes than 
security and may provide an important positive, organismic framework for understanding developmental and interpersonal processes. Indeed, even within attachment theory, autonomy is considered to be a key characteristic of the kind of caregiving relationship that fosters security (Ainsworth, 1973; Belsky, 2006; Bretherton, 1987), suggesting its logical if not developmental priority over security. These issues, however, require further research, ideally longitudinal in nature.

Another finding with relevance to the study of human development concerns the association between autonomy and emotional reliance. Notably, in this sample of young adults, being highly autonomous was associated with being more willing rather than less willing to turn to one's partners (including one's parents) for emotional support. This is important because some have argued that emotional autonomy, construed as relying less and less on parental supports, is a normative aspect of adolescent development (Steinberg \& Silverberg, 1986). In their research, however, Ryan and Lynch (1989) distinguished autonomy from detachment or independence and argued that "growth in ... autonomy does not necessarily require severing emotional ties with parents or nonutilization of the emotional support parents can afford" (p. 355). The present findings lend further support to this argument.

\section{Promoting Security and Autonomy in the Client- Counselor Relationship}

For counselors, it may be possible to derive an interesting analogy from the present research. Just as attachment theory suggests that a secure relationship with the caregiver provides the base from which the child can explore the environment, returning to base during times of danger or stress, so counselors have long understood the importance of providing security, or safety, to their clients. Indeed, safety is a key element in fostering rapport, considered essential in helping clients to explore issues and areas of themselves in which they feel vulnerable (Cormier \& Hackney, 2012; Karasu, 1992; Ryan, Lynch, Vansteenkiste, \& Deci, 2011; Schafer, 1983; Yalom, 2002). Attending to issues of safety in the counseling relationship is especially important when working with clients whose trust has been broken at some point in the past, as in cases of abuse or other forms of trauma (Lynch, 2012a), or with clients who "do not have privileges and power from the mainstream culture and who have a history of discrimination and oppression" (Cormier \& Hackney, 2012, p. 39). For counselors, the key skills they need to promote client safety are those needed to create the "necessary and sufficient conditions" for establishing a therapeutic relationship, identified many years ago by Rogers (1961) as empathy, genuineness, and unconditional positive regard. Developing and honing these skills is part and parcel of the training of virtually every counselor.

Perhaps a more novel contribution of the present study for counselors is the attention it calls to the role of autonomy and autonomy support in interpersonal relationships. Indeed, as previously noted, the study found that the contribution of the autonomy dimension to emotional reliance on others and to vitality in relationships was even more substantial than that of security. That in itself may be sufficient reason for counselors to consider the value of attending to issues of autonomy when working with their clients. In fact, recent developments in theory and research have highlighted the importance of autonomy as a motivational construct in counseling (Lynch, Vansteenkiste, Deci, \& Ryan, 2011; Ryan et al., 2011). In the following sections, I expand on the findings of the present study, drawing on existing empirical and theoretical work that applies SDT to therapy (Britton, Williams, \& Conner, 2008; Lynch et al., 2011; Ryan et al., 2011; Zuroff et al., 2007); interested readers may find similar principles in work that applies SDT to other fields, such as education (Vansteenkiste, Simons, Lens, Sheldon, \& Deci, 2004) and health care (Ryan, Patrick, Deci, \& Williams, 2008). On the basis of these sources, I suggest that the construct of autonomy and its connection to emotional reliance may provide an important way for counselors to think about the nature of client motivation for counseling. In addition, from the theoretical and empirical literature on autonomy, recommendations can be drawn for case conceptualization, intervention, and assessment.

Autonomy and client motivation for counseling. The present study found that people were more willing to turn to partners for emotional support, and experienced more vitality in their relationships, when they themselves felt more autonomous and when they experienced their partners as supporting their autonomy. This last point, pertaining to the within-person process linking emotional reliance and vitality with interpersonal support for autonomy, is perhaps the most relevant one for counselors to consider in their work because it suggests that their way of interacting with their clients can affect the quality of clients' motivation for counseling. The present research tested the link between autonomy support and emotional reliance in the context of everyday relationships; that link remains to be tested specifically within the client-counselor relationship. It seems reasonable, however, to expect that the client-counselor relationship is a mirror of the kind of processes that describe relationships in general (Rogers, 1961; Yalom, 2002). In this light, clients may be more willing to turn to their counselor for needed supports when their motivation for counseling is more autonomous and when they experience their counselor as autonomy supportive.

Prior research has, in fact, identified important benefits for clients when their motivation for counseling is autonomous: They tend to stay in therapy longer, to derive more benefit from therapy, and to maintain therapy-related change longer than clients whose motivation for therapy is pressured or controlled (Lynch et al., 2011; Ryan et al., 2011). Furthermore, the research suggests that counselors' way of being with the client can have a direct impact on the quality of the client's motivation for counseling. Specifically, when clients experience their therapist as being autonomy supportive (rather than 
controlling), their motivation for participating in their own therapy tends to become more internal and self-regulated, that is, more autonomous. Within the SDT framework, motivation is dynamic and responsive to cues and affordances in the interpersonal environment. Thus, when counselors are autonomy supportive with their clients, there may be at least two important results: (a) They may help their clients to become more autonomous in their motivation for counseling, which, as noted, in itself has benefits for the client, and (b) on the basis of findings of the present study, they may help their clients to demonstrate greater willingness to turn to the counselor in a time of need (i.e., to show greater emotional reliance). The possibility that counselor autonomy support can help clients to find more internal, personally valued reasons for participating in counseling may be especially important when clients come to counseling for reasons that are initially more external or even involuntary, such as clients mandated for treatment by the courts or children brought to the counselor's office by a parent or guardian. Thus, there may indeed be numerous reasons for counselors to attend to the quality of their clients' motivation for counseling. To frame this issue within a wider context, in a recent review article on motivation in counseling and psychotherapy, Ryan et al. (2011) maintained that virtually all approaches, including psychodynamic, cognitive behavioral, and humanistic, either implicitly or explicitly acknowledge the benefits and desirability of autonomous motivation for clients. If this is indeed the case, how can counselors become more autonomy supportive in their work with clients?

In practice, autonomy can be promoted in a number of ways in the context of the counseling relationship (Lynch \& Levers, 2007; Lynch et al., 2011; Ryan et al., 2011). First, the practice of empathic listening skills (Patterson \& Joseph, 2007; Rogers, 1961) provides the crucial foundation for an autonomy supportive stance on the part of the counselor. As noted earlier, interest in the other's perspective is an essential component of autonomy support. Closely linked to this is refraining from using language that might be perceived by the client to be judgmental or controlling, attitudes that undermine the experience of autonomy. In addition, because autonomy support presupposes provision of choice, counselors can attend to the ways in which they are able to encourage their clients to make choices for themselves in the context of the counseling relationship, perhaps in terms of setting the goals of treatment or simply as deciding where to begin this week's session. On the perhaps rare occasions when the counselor must be more directive, such as in a situation where there is a potential for self-harm or when the client has limited ego strength, providing a rationale for counselor-initiated directives can help the client to experience those directives as providing structure and safety while minimizing the autonomy-undermining sense of external pressure or control that directives typically convey. Understanding why a particular course of action might be of value to the individual, which is the purpose of providing a rationale, helps to foster a sense of choice and therefore autonomy in enacting the directive (Lynch \& Levers, 2007).

Because motivation for any activity can change over time and from situation to situation, it seems important that counselors attend to the quality of their clients' motivation for being in counseling not only at the beginning of their work together but in an ongoing way: Does the client's motivation seem to be more autonomous, reflecting awareness of choice and valuing of the personal importance of counseling for the client, or does the client's motivation seem to be controlled, coerced, pressured, or introjected? What might be going on in the client's life, or in the relationship between the client and counselor, that might be shaping the client's motivation in one direction or another? By maintaining an autonomy supportive attitude, counselors can hope to facilitate motivation that is more internal and autonomous among their clients.

It seems important to point out that, as a way of conceptualizing client motivation for counseling, the construct of autonomy has relevance across theoretical orientations, modalities, contexts, populations, and problems, as Ryan et al. (2011) observed. Indeed, as some have argued, it may prove to be a new nonspecific factor in counseling (Scheel, 2011; Zuroff et al., 2007). Providing support for autonomy may have another benefit of value to counselors, in addition to those noted earlier. To return to the analogy with which this section of the Discussion began, borrowed from the attachment theory tradition, I suspect it likely that, because autonomy support is one of the parenting qualities that attachment theorists believe is essential in promoting a secure attachment, so autonomy supportive counseling may ultimately foster the kind of client-counselor relationship that will, in turn, engender trust, security, and safety in the client. Again, autonomy and security go hand in hand.

Autonomy and case conceptualization, intervention, and assessment. The literature suggests the construct of autonomy may also be useful in helping counselors with case conceptualization, intervention, and assessment. Because this direction moves further away from the core of the current study, these applications will be treated only briefly here.

As noted, within SDT, autonomy is considered to be a basic psychological need. The notion of autonomy as a basic need may provide a useful framework for counselors in conceptualizing the nature of the problems that clients experience as well as in designing relevant interventions. I find Basch's (1995) developmental model of psychotherapy to provide a useful example of how one might incorporate the construct of needs in therapy; interestingly, his model includes both autonomy and attachment as sectors of development, in a way that is analogous to SDT's concept of needs. To focus on autonomy, in the course of their conversations with clients, counselors can listen for clues as to how the need for autonomy was satisfied in their early caregiver relationship, as well as in their romantic and nonromantic friendships, in their career and work experiences, and so on, both historically and in the present. If, 
as SDT argues, autonomy is a basic psychological need, then chronic experiences of need deprivation can be expected to have important implications for client well-being and functioning; the more prolonged or profound the deprivation, the more serious the consequences for development. Research on the developmental consequences of need deprivation is just beginning to take place, but initial results suggest that need deprivation may indeed have a profound impact on the emergence of certain problematic or even pathological forms of behavior, self-regulation, and identity formation (Ryan, Deci, Grolnick, \& La Guardia, 2006). Although uncovering blockages (both intrapsychic and interpersonal) to the exercise of choice is part and parcel of case conceptualization and the therapeutic process in general, counselors can use the construct of autonomy as a basic need to shape relevant interventions. For example, counselors can help their clients to identify ways in which they can make meaningful choices in their daily lives, bringing their experiences of success or failure back to counseling as grist for the mill. In other words, to the extent that problems in satisfying the need for autonomy are relevant to the client's presentation, counselors can design strategies to help clients recognize and exercise opportunities for autonomy in their daily lives, with the expectation that satisfaction of this basic need will yield benefits to the client on multiple levels, developmentally, interpersonally, and in terms of well-being.

Regarding assessment, Pelletier, Tuson, and Haddad (1997) developed a scale to measure client motivation for therapy in terms of relative autonomy. Counselors might use this scale at various points in their work with clients, or they might choose to assess client motivation less formally and more qualitatively, by becoming more familiar with the concept of autonomy as it continues to be refined in the counseling literature. It is of critical importance, however, when working with clients to bear in mind the important distinction between autonomy and either independence or detachment (Ryan \& Lynch, 1989). Autonomy is about the experience of choice, endorsing one's actions at a deep level of reflection, and congruence between one's actions and one's personal values and beliefs. However counselors choose to assess client motivation, the research suggests that quality of motivation, that is, the degree to which it is autonomous versus pressured or controlled, has implications for persistence in counseling, for the benefits one receives from counseling, and for the maintenance of positive change over time. The quality of clients' motivation for counseling should be of considerable interest to their counselors.

\section{Limitations and Future Directions}

There are some important limitations in the present study. Among them is the fact that the data are self-report and correlational. For that reason, it is not possible to make claims about causality. In addition, given the nature of the sample (undergraduate students, with gender and ethnic composition that may not reflect that of the wider population), the results may not be generalizable to other groups. In addition, the relatively small proportion of male participants in the sample (approximately 19\%) may have made it difficult to detect potential interactions by gender. To confirm and extend the present findings researchers will need to conduct further studies, ideally longitudinal in nature and involving multiple reporters, with other samples that are both more diverse and more representative with respect to age, gender, and ethnicity. Because the present research focused on everyday interpersonal relationships, an important line for future inquiry would be to explore the role of emotional reliance specifically within the client-counselor relationship. I expect that the kind of interpersonal process identified in the present study, linking emotional reliance with autonomy and security, will also be found in the client-counselor relationship, in line with the premise that the client-therapist relationship mirrors more everyday relationship processes (Rogers, 1961; Yalom, 2002), but it will be important to test that prediction.

\section{Summary}

The present study confirmed the presence of a within-person process linking emotional reliance, or the willingness to turn to one's partners during an emotionally salient event, to both attachment security and autonomy. In addition, the study confirmed previous results showing that willingness to turn to one's partners was positively associated with well-being, here measured as vitality within relationships. Counselors are encouraged to consider how they might promote both security and autonomy in their work with clients.

\section{References}

Ainsworth, M. D. (1973). The development of infant-mother attachment. In B. M. Caldwell \& H. N. Ricciuti (Eds.), Review of child development research: Vol. 3 (pp. 1-94). Chicago, IL: University of Chicago Press.

Baldwin, M. W., Keelan, J. P. R., Fehr, B., Enns, V., \& Koh-Rangarajoo, E. (1996). Social-cognitive conceptualization of attachment working models: Availability and accessibility effects. Journal of Personality and Social Psychology, 71, 94-109.

Balkin, R. S., \& Sheperis, C. J. (2011). Evaluating and reporting statistical power in counseling research. Journal of Counseling \& Development, 89, 268-272.

Bartholomew, K., \& Horowitz, L. M. (1991). Attachment styles among young adults: A test of a four-category model. Journal of Personality and Social Psychology, 61, 226-244.

Basch, M. F. (1995). Doing brief psychotherapy. New York, NY: Basic Books.

Belsky, J. (2002). Developmental origins of attachment styles. Attachment and Human Development, 4, 166-170.

Belsky, J. (2006). Determinants and consequences of infant-parent attachment. In L. Balter \& C. S. Tamis-LeMonda (Eds.), Child psychology: A handbook of contemporary issues (2nd ed., pp. 53-77). New York, NY: Psychology Press. 
Bostic, T. J., Rubio, D., \& Hood, M. (2000). A validation of the Subjective Vitality Scale using structural equation modeling. Social Indicators Research, 52, 313-324.

Bowlby, J. (1973). Attachment and loss: Vol. 2. Separation: Anxiety and anger. New York, NY: Basic Books.

Brennan, K. A., Clark, C. L., \& Shaver, P. R. (1998). Self-report measurement of adult attachment: An integrative overview. In J. A. Simpson \& W. S. Rholes (Eds.), Attachment theory and close relationships (pp. 46-76). New York, NY: Guilford Press.

Bretherton, I. (1987). New perspectives on attachment relations: Security, communication and internal working models. In J. Osofsky (Ed.), Handbook of infant development (pp. 1061-1100). New York, NY: Wiley.

Britton, P. C., Williams, G. C., \& Conner, K. R. (2008). Selfdetermination theory, motivational interviewing, and the treatment of clients with acute suicidal ideation. Journal of Clinical Psychology, 64, 52-66.

Cohen, S., Sherrod, D. R, \& Clark, M. S. (1986). Social skills and the stress-protective role of social support. Journal of Personality and Social Psychology, 50, 963-973.

Cormier, S., \& Hackney, H. (2012). Counseling strategies and interventions (8th ed.). Boston, MA: Allyn \& Bacon.

Fleeson, W. (2007). Studying personality processes: Explaining change in between-persons longitudinal and within-person multilevel models. In R. W. Robins, R. C. Fraley, \& R. F. Krueger (Eds.), Handbook of research methods in personality psychology (pp. 523-542). New York, NY: Guilford Press.

Florian, V., Mikulincer, M., \& Bucholtz, I. (1995). Effects of adult attachment style on the perception and search for social support. Journal of Psychology, 129, 665-676.

Grow, V., Sheldon, K., \& Ryan, R. (1994). Trait self-determination and resistance to peer pressure. Unpublished manuscript, University of Rochester, Rochester, NY.

Hazan, C., \& Shaver, P. R. (1987). Romantic love conceptualized as an attachment process. Journal of Personality and Social Psychology, 52, 511-524.

Hazan, C., \& Shaver, P. R. (1994). Attachment as an organizational framework for research on close relationships. Psychological Inquiry, 5, 1-22.

Karasu, T. B. (1992). Wisdom in the practice of psychotherapy. New York, NY: Basic Books.

Kobak, R. (1994). Adult attachment: A personality or a relationship construct? Psychological Inquiry, 5, 42-44.

La Guardia, J. G., Ryan, R. M., Couchman, C. E., \& Deci, E. L. (2000). Within-person variation in security of attachment: A self-determination theory perspective on attachment, need fulfillment, and well-being. Journal of Personality and Social Psychology, 79, 367-384.

Lynch, M. F. (2012a). Theoretical contexts of trauma counseling. In L. L. Levers (Ed.), Trauma counseling: Theories and interventions (pp. 47-58). New York, NY: Springer.

Lynch, M. F. (2012b). Using multilevel modeling in counseling research. Measurement and Evaluation in Counseling and Development, 45, 211-224.
Lynch, M. F., La Guardia, J. G., \& Ryan, R. M. (2009). On being yourself in different cultures: Ideal and actual self-concept, autonomy support, and well-being in China, Russia, and the United States. The Journal of Positive Psychology, 4, 290-304.

Lynch, M. F., \& Levers, L. L. (2007). Ecological-transactional and motivational perspectives in counseling. In J. Gregoire \& C. Jungers (Eds.), The counselor's companion: What every beginning counselor needs to know (pp. 586-605). Mahwah, NJ: Erlbaum.

Lynch, M. F., Vansteenkiste, M., Deci, E. L., \& Ryan, R. M. (2011). Autonomy as process and outcome: Revisiting cultural and practical issues in motivation for counseling. The Counseling Psychologist, 39, 286-302.

Markus, H. R., \& Kitayama, S. (1991). Culture and the self: Implications for cognition, emotion, and motivation. Psychological Review, 98, 224-253.

Mikulincer, M., \& Shaver, P. R. (2007). Boosting attachment security to promote mental health, prosocial values, and inter-group tolerance. Psychological Inquiry, 18, 139-156.

NICHD Early Childcare Research Network. (2006). Infant-mother attachment classification: Risk and protection in relation to changing maternal caregiving quality. Developmental Psychology, 42, 38-58.

Patterson, P. G., \& Joseph, S. (2007). Person-centered personality theory: Support from self-determination theory and positive psychology. Journal of Humanistic Psychology, 47, 117-139.

Pelletier, L. G., Tuson, K. M., \& Haddad, N. K. (1997). Client Motivation for Therapy Scale: A measure of intrinsic motivation, extrinsic motivation, and amotivation for therapy. Journal of Personality Assessment, 68, 414-435.

Pierce, G. R., Sarason, I. G., \& Sarason, B. R. (1991). General and relationship-based perceptions of social support: Are two constructs better than one? Journal of Personality and Social Psychology, 61, 1028-1039.

Powell, G. N., \& Kotschessa, B. (1995). Factors that influence professional employees' willingness to seek counseling. Psychological Reports, 77, 872-874.

Reise, S. P., \& Duan, N. (1999). Multilevel modeling and its application in counseling psychology research. The Counseling Psychologist, 27, 528-551.

Rickwood, D. J., \& Braithwaite, V. A. (1994). Social-psychological factors affecting help-seeking for emotional problems. Social Science \& Medicine, 39, 563-572.

Robbins, J. M., \& Greenley, J. R. (1983). Thinking about what's wrong: Attributions of severity, cause, and duration in the problem definition stage of psychiatric help-seeking. Research in Community \& Mental Health, 3, 209-232.

Rogers, C. R. (1961). On becoming a person: A therapist's view of psychotherapy. Boston, MA: Houghton Mifflin.

Ryan, R. M. (1993). Agency and organization: Intrinsic motivation, autonomy, and the self in psychological development. In J. Jacobs (Ed.), Nebraska symposium on motivation: Developmental perspectives on motivation (Vol. 40, pp. 1-56). Lincoln: University of Nebraska Press. 
Ryan, R. M., Brown, K. W., \& Creswell, J. D. (2007). How integrative is attachment theory? Unpacking the meaning and significance of felt security. Psychological Inquiry, 18, 177-182.

Ryan, R. M., \& Deci, E. L. (2000a). The darker and brighter sides of human existence: Basic psychological needs as a unifying concept. Psychological Inquiry, 11, 319-338.

Ryan, R. M., \& Deci, E. L. (2000b). Self-determination theory and the facilitation of intrinsic motivation, social development, and well-being. American Psychologist, 55, 68-78.

Ryan, R. M., Deci, E. L., Grolnick, W. S., \& La Guardia, J. G. (2006). The significance of autonomy and autonomy support in psychological development and psychopathology. In D. Cicchetti \& D. J. Cohen (Eds.), Developmental psychopathology: Theory and method (pp. 795-849). Hoboken, NJ: Wiley.

Ryan, R. M., \& Frederick, C. (1997). On energy, personality, and health: Subjective vitality as a dynamic reflection of well-being. Journal of Personality, 65, 529-565.

Ryan, R. M., La Guardia, J. G., Solky-Butzel, J., Chirkov, V., \& Kim, Y. (2005). On the interpersonal regulation of emotions: Emotional reliance across gender, relationships, and cultures. Personal Relationships, 12, 145-163.

Ryan, R. M., \& Lynch, J. (1989). Emotional autonomy versus detachment: Revisiting the vicissitudes of adolescence and young adulthood. Child Development, 60, 340-356.

Ryan, R. M., Lynch, M. F., Vansteenkiste, M., \& Deci, E. L. (2011). Motivation and autonomy in counseling, psychotherapy, and behavior change: A look at theory and practice. The Counseling Psychologist, 39, 193-260.

Ryan, R. M., Patrick, H., Deci, E. L., \& Williams, G. C. (2008). Facilitating health behaviour change and its maintenance: Interventions based on self-determination theory. The European Health Psychologist, 10, 2-5.

Sarason, I. G., Pierce, G. R., \& Sarason, B. R. (1990). Social support and interactional processes: A triadic hypothesis. Journal of Social and Personal Relationships, 7, 495-506.

Schafer, R. (1983). The analytic attitude. New York, NY: Basic Books.

Scheel, M. J. (2011). Client common factors represented by client motivation and autonomy. The Counseling Psychologist, 39, 193-285.

Shaver, P. R., Belsky, J., \& Brennan, K. A. (2000). The Adult Attachment Interview and self-reports of romantic attachment: Associations across domains and methods. Personal Relationships, 7, 25-43.

Sheldon, K. M., \& Deci, E. L. (1996). The Self-Determination Scale. Unpublished manuscript, University of Rochester, Rochester, NY.
Sheldon, K. M., Ryan, R. M., \& Reis, H. (1996). What makes for a good day? Competence and autonomy in the day and in the person. Personality and Social Psychology Bulletin, 22, 1270-1279.

Snijders, T.A. B. (2005). Power and sample size in multilevel linear models. In B. S. Everitt \& D. C. Howell (Eds.), Encyclopedia of statistics in behavioral science (Vol. 3, pp. 1570-1573). Chicago, IL: Wiley.

Sroufe, L. A., Fox, N. E., \& Pancake, V. R. (1983). Attachment and dependency in developmental perspective. Child Development, $54,1615-1627$.

Steinberg, S., \& Silverberg, S. B. (1986). The vicissitudes of autonomy in early adolescence. Child Development, 57, 841-851.

Thrash, T. M., \& Elliot, A. J. (2002). Implicit and self-attributed achievement motives: Concordance and predictive validity. Journal of Personality, 70, 729-755.

Vansteenkiste, M., Niemiec, C. P., \& Soenens, B. (2010). The development of the five mini-theories of self-determination theory: An historical overview, emerging trends, and future directions. In T. C. Urdan \& S. A. Karabenick (Eds.), The decade ahead: Theoretical perspectives on motivation and achievement (pp. 105-165). Bingley, United Kingdom: Emerald Group.

Vansteenkiste, M., Simons, J., Lens, W., Sheldon, K. M., \& Deci, E. L. (2004). Motivating learning, performance, and persistence: The synergistic role of intrinsic goals and autonomy-support. Journal of Personality and Social Psychology, 87, 246-260.

Vogel, D. L., \& Wei, M. (2005). Adult attachment and help-seeking intent: The mediating roles of psychological distress and perceived social support. Journal of Counseling Psychology, 52, 347-357.

Vogel, D. L., \& Wester, S. R.. (2003). To seek help or not to seek help: The risks of self-disclosure. Journal of Counseling Psychology, 50, 351-361.

Wallace, J. L., \& Vaux, A. (1993). Social support network orientation: The role of adult attachment style. Journal of Social and Clinical Psychology, 12, 354-365.

Williams, G. C., \& Deci, E. L. (2001). Activating patients for smoking cessation through physician autonomy support. Medical Care, 39, 813-823.

Williams, G. C., Lynch, M. F., McGregor, H., Ryan, R. M., Sharp, D., \& Deci, E. L. (2006). Validation of the Important Other Climate Questionnaire: Assessing autonomy support for health related change. Families, Systems, and Health, 24, 179-194.

Yalom, I. D. (2002). The gift of therapy: An open letter to a new generation of therapists and their patients. New York, NY: HarperCollins.

Zuroff, D. C., Koestner, R., Moskowitz, D. S., McBride, C., Bagby, M., \& Marshall, M. (2007). Autonomous motivation for therapy: A new non-specific predictor of outcome in brief treatments of depression. Psychotherapy Research, 17, 137-148. 